\title{
Real and potential distribution of the hyperparasitoid genus Mesochorus Gravenhorst (Ichneumonidae: Mesochorinae) in Brazil
}

\section{Distribución real y potencial del género hiperparasitoide Mesochorus Gravenhorst (Ichneumonidae: Mesochorinae) en Brasil}

\author{
Rodrigo O. Araujo ${ }^{1,2}$, Rubén Garrido ${ }^{1}$, José N. Mesquita-Neto ${ }^{1,2}$ \& Víctor H. Monzón ${ }^{1 *}$ \\ ${ }^{1}$ Laboratorio de Ecología de Abejas, Departamento de Ciencias Biológicas y Químicas, Facultad de Ciencias Básicas, Universidad Católica del Maule, Talca, Chile. \\ ${ }^{2}$ Centro de Investigación de Estudios Avanzados del Maule, Vicerrectoría de Investigación y Postgrado, Universidad Católica del Maule, Talca, Chile. \\ *Email: vmonzon@ucm.cl
}

\begin{abstract}
Mesochorus species are hyperparasitoids capable of nullifying biological control agents. This study is the first to map and predict the distribution of this genus in Brazil. Species distribution modeling was used to estimate the potential distribution of Mesochorus. We obtained 72 occurrence records of 49 Mesochorus species, being 30 endemics. According to our prediction model, this genus can be distributed in all Brazilian biomes, with higher suitability of occurrence in the Atlantic Forest and lower in the Caatinga and Pampa.
\end{abstract}

Keywords: Ichneumonoidea, parasitoid wasp, species distribution modeling.

\section{RESUMEN}

Las especies de Mesochorus son hiperparasitoides capaces de anular los agentes de control biológico. Este estudio es el primero en mapear y predecir la distribución de este género en Brasil. Se utilizó un modelo de distribución de especies para estimar la distribución potencial de Mesochorus. Obtuvimos 72 registros de ocurrencia de 49 especies de Mesochorus, siendo 30 endémicas. De acuerdo con nuestro modelo de predicción, este género se puede distribuir en todos los biomas brasileños, con una mayor idoneidad de ocurrencia en el Bosque Atlántico y menor en la Caatinga y Pampa.

Palabras clave: avispa parasitoide, Ichneumonoidea, modelación de distribución de especies.

The genus Mesochorus Gravenhorst is by far the largest of the subfamily Mesochorinae, with approximately 700 species (Yu et al. 2012). Being secondary parasitoids, also known as hyperparasitoids, this genus attacks many species of primary parasitoids in a variety of lepidopteran, coleopteran, and other hosts (Yeargan \& Braman 1989).

Most insects that are parasitoid of other insects are themselves attacked by hyperparasitoids. However, hyperparasitoids have been much less studied in nature, compared with the primary parasitoids (Day 2002). This is probably the result of several factors: most field studies of parasites are a major part of biological control studies, which are directed toward reducing the abundance of a plant pest, so the focus is on the primary parasitoids which may reduce pest densities (Day 2002). The hyperparasitism is an important factor to be considered in places that implement the biological control of pests, since it is traditionally been viewed as injurious to biological control efforts as the hyperparasitoid may limit populations of the beneficial primary parasitoid (Ashfaq et al. 2005).

Despite their potentially serious effect on primary parasitoids involved in biological control, there have been few biological studies of Mesochorus species (Yeargan \& Braman 1989). Considering the deleterious effect of this genus on biological pest control, this study aims to be the first to map and predict the potential distribution of this hyperparasitoid genus in Brazil using a species distribution modeling. 
We gathered distributional data on Mesochorus species in Brazil from literature records and online databases [Taxonomic Catalog of the Brazilian Fauna (Fernandes et al. 2018), Taxapad 2012 (Yu et al. 2012)]. Geographic coordinates (decimals degrees) were obtained from the species occurrence data informed in the studied literature (Table 1). For records lacking the exact sampling site information, we used Google Earth (Google Inc. 2012) to find city center coordinates as proxy information for sampling sites. All these compiled data allowed the spatial location and thus the relation of these with the environmental data.

The study area of this work considers the geographic distribution of Mesochorus species in Brazil and is projected to Central America and South America. Concerning the input data for the model, it was chosen as $M$ area (Barve et al. 2011) the biomes where Mesochorus species have been found in Brazil, following the current official classification of vegetation in Brazil by IBGE (2004): Amazonia , Atlantic Forest (with inserted discontinuous grassland areas, especially on plateau sites in its southern part), Caatinga, Cerrado, Pantanal and Pampa.

The environmental variables are obtained from the Worldclim website (Hijmans et al. 2005). Based on a correlation analysis (Spearman's correlation) among the 19 bioclimatic Wordclim variables (Peterson et al. 2011), the four variables that presented the lowest correlation among themselves were chosen: Annual Mean Temperature; Temperature Seasonality (standard deviation *100); Precipitation Seasonality (Coefficient of Variation) and Annual Precipitation. Environmental layers of 30 seconds resolution (approximately $1 \mathrm{~km}^{2}$ ) were used. R project 3.4 .1 was used for the analysis of correlation between environmental variables.

The species distribution model used for potential distribution of the Mesochorus in Brazil corresponds to Maxent (Phillips et al. 2006), one of the most occupied software`s for species distribution modelling (Qiao et al. 2015; Merow et al. 2013). Maxent corresponds to a matching-learning method where the maximum entropy function is used, predicting ideal species areas using occurrences and environmental variables (Elith et al. 2011; Philips et al. 2006). We used the following configuration (Anderson 2013; Owens et al. 2013; Peterson et al. 2011): the auto features function is chosen, jackknife is performed for the variables, response curves are generated, and the output of the model is logistic. Also, the functions clamping and extrapolate are turned off.

Regarding the model evaluation, crossvalidate with 7 replicas was used. The behavior of the model was evaluated using AUC -Area under the ROC curve- (Phillips et al. 2006). The AUC value ranges from 0.5 to 1 , for models that fit better than chance. The model performs better when the values are closer to 1 (Phillips et al. 2006).

A total of 72 occurrence records of 49 Mesochorus species were obtained according to available literature (Fernandes et al. 2018; Dasch 1974; Say 1835), of which 30 are endemic to Brazil. The list of species that occur in Brazil, as well as their respective distribution (in geographical coordinates) can be observed in Table 1.

Considering the potential occurrence area of the Mesochorus species considered in this study, it is observed through its potential distribution that this genus is better represented in the Neotropical Region (sensu Morrone 2014), being less represented in the Andean biogeographic zone (sensu Morrone 2015). This distribution pattern corroborates what has been suggested by Dasch (1974) and Hanson \& Gauld (2006). Although the potential distribution pattern corroborates the standard distribution cited in the literature, we focus on the potential and real distribution of Mesochorus in Brazil, since only Brazilian species were considered.

Among the 49 Mesochorus species recorded for Brazil, 46 occur in the Atlantic Forest biome (44 exclusives), the others three occurring in the Amazon (M. paraensis Dasch), Caatinga (M. bahiae Dasch) and Cerrado (M. caribbeanus Dasch) biomes. Considering the potential distribution of Mesochorus, it is estimated that this genus can be found in all Brazilian biomes, being the least suitable areas of occurrence in the Caatinga and Pampa, and more suitable in the Atlantic Forest (Figure 1). Both the real and potential distribution of the studied species reinforce that the Atlantic Forest biome combines unique biotic and abiotic characteristics, being considered the Brazilian biome with the greatest biodiversity and the fourth biodiversity hotspot among the 25 most important of the world (Myers et al. 2000).

Some studies consider hyperparasitoids as potential targets in biological control and investigate methods to buffer their negative impacts on pest suppression (Tougeron \& Tena 2018). As species at high trophic levels, hyperparasitoids undergo many ecological and physiological constraints on which we could act to reduce their fitness or their establishment and persistence in the target environment (Tougeron \& Tena 2018).

Observing the potential distribution of this genus, it is probable that the number of Brazilian Mesochorus species is underestimated, since most of the specimens collected in the field and/or from the creation of pest insects remain identified at the genus level. The mapping of occurrence areas as well as species identification are fundamental to clarify the effects (positive and/or negative) of these hyperparasitoids on the biological control of pest species present in the different crops of great economic importance for Brazil, thus providing subsidies for biological control of pests and systematic studies. 
TABLE 1. Geographical coordinates of the distribution of Mesochorus in Brazil (decimal degrees), endemic species highlighted with an asterisk (*). / Coordenadas geográficas de la distribución de Mesochorus en Brasil (grados decimales), especies endémicas resaltadas con un asterisco $\left({ }^{*}\right)$.

\begin{tabular}{|c|c|c|c|}
\hline Specie & Latitud & Longitud & Reference \\
\hline Mesochorus abruptus Dasch* & $-27.070768^{\circ}$ & $-52.403724^{\circ}$ & Dasch 1974 \\
\hline M. absonus Dasch* & $-27.070440^{\circ}$ & $-52.371788^{\circ}$ & Dasch 1974 \\
\hline M. amoenus Dasch* & $-27.090301^{\circ}$ & $-52.346317^{\circ}$ & Dasch 1974 \\
\hline \multirow[t]{6}{*}{ M. angustistigmatus Dasch } & $-8.287476^{\circ}$ & $-35.970105^{\circ}$ & Dasch 1974 \\
\hline & $-22.369617^{\circ}$ & $-44.628541^{\circ}$ & \\
\hline & $-27.091391^{\circ}$ & $-52.372335^{\circ}$ & \\
\hline & $-22.970785^{\circ}$ & $-43.452009^{\circ}$ & \\
\hline & $-22.745047^{\circ}$ & $-44.569384^{\circ}$ & \\
\hline & $-22.427484^{\circ}$ & $-42.973118^{\circ}$ & \\
\hline M. argutus Dasch* & $-22.949105^{\circ}$ & $-43.287261^{\circ}$ & Dasch 1974 \\
\hline M. bahiae Dasch* & $-15.250734^{\circ}$ & $-40.244126^{\circ}$ & Dasch 1974 \\
\hline M. bocainensis Dasch* & $-22.743788^{\circ}$ & $-44.587945^{\circ}$ & Dasch 1974 \\
\hline M. brasiliensis Dasch* & $-22.431498^{\circ}$ & $-42.987610^{\circ}$ & Dasch 1974 \\
\hline M. caribbeanus Dasch & $-15.739142^{\circ}$ & $-47.927764^{\circ}$ & Dasch 1974 \\
\hline M. cingulatus Dasch & $-27.102512^{\circ}$ & $-52.385047^{\circ}$ & Dasch 1974 \\
\hline M. concavus Dasch* & $-27.106123^{\circ}$ & $-52.412184^{\circ}$ & Dasch 1974 \\
\hline \multirow[t]{4}{*}{ M. convexus Dasch } & $-22.758794^{\circ}$ & $-44.597053^{\circ}$ & Dasch 1974 \\
\hline & $-2.447788^{\circ}$ & $-43.000434^{\circ}$ & \\
\hline & $-7.121343^{\circ}$ & $-52.412884^{\circ}$ & \\
\hline & $-5.513692^{\circ}$ & $-49.313746^{\circ}$ & \\
\hline \multirow[t]{2}{*}{ M. cubensis Dasch } & $-27.134097^{\circ}$ & $-52.422743^{\circ}$ & Dasch 1974 \\
\hline & $4.193908^{\circ}$ & $-60.793438^{\circ}$ & \\
\hline M. deltoides Dasch* & $-27.049648^{\circ}$ & $-52.399678^{\circ}$ & Dasch 1974 \\
\hline \multirow[t]{8}{*}{ M. discitergus Say } & $-25.287520^{\circ}$ & $-49.074391^{\circ}$ & Say 1835 \\
\hline & $-22.909310^{\circ}$ & $-47.050075^{\circ}$ & \\
\hline & $-22.898986^{\circ}$ & $-43.021904^{\circ}$ & \\
\hline & $-27.144362^{\circ}$ & $-52.396715^{\circ}$ & \\
\hline & $-25.540012^{\circ}$ & $-49.249350^{\circ}$ & \\
\hline & $-22.732851^{\circ}$ & $-44.610365^{\circ}$ & \\
\hline & $-22.460077^{\circ}$ & $-43.004886^{\circ}$ & \\
\hline & $-1.426025^{\circ}$ & $-48.442344^{\circ}$ & \\
\hline M. facetus Dasch* & $-22.923927^{\circ}$ & $-43.467352^{\circ}$ & Dasch 1974 \\
\hline M. ferrugineus Dasch* & $-27.147982^{\circ}$ & $-52.362060^{\circ}$ & Dasch 1974 \\
\hline \multirow[t]{2}{*}{ M. glaucus Dasch } & $-27.148692^{\circ}$ & $-52.330262^{\circ}$ & Dasch 1974 \\
\hline & $-25.541584^{\circ}$ & $-49.305956^{\circ}$ & \\
\hline
\end{tabular}




\begin{tabular}{|c|c|c|c|}
\hline Specie & Latitud & Longitud & Reference \\
\hline \multirow[t]{2}{*}{ M. grandidentatus Dasch } & $-17.879205^{\circ}$ & $-51.725602^{\circ}$ & Dasch 1974 \\
\hline & $-27.163553^{\circ}$ & $-52.342290^{\circ}$ & \\
\hline M. hilaris Dasch* & $-22.942968^{\circ}$ & $-43.444094^{\circ}$ & Dasch 1974 \\
\hline M. impuctatus Dasch & $-22.943856^{\circ}$ & $-43.499158^{\circ}$ & Dasch 1974 \\
\hline M. inaequalis Dasch* & $-27.163264^{\circ}$ & $-52.369567^{\circ}$ & Dasch 1974 \\
\hline M. infensus Dasch* & $-27.157679^{\circ}$ & $-52.391446^{\circ}$ & Dasch 1974 \\
\hline M. insolitus Dasch & $-27.153935^{\circ}$ & $-52.411073^{\circ}$ & Dasch 1974 \\
\hline M. inurbanus Dasch* & $-27.149938^{\circ}$ & $-52.432348^{\circ}$ & Dasch 1974 \\
\hline M. junctus Dasch* & $-27.158114^{\circ}$ & $-52.451048^{\circ}$ & Dasch 1974 \\
\hline M. longicoleus Dasch* & $-22.774114^{\circ}$ & $-44.605170^{\circ}$ & Dasch 1974 \\
\hline \multirow[t]{2}{*}{ M. longidens Dasch* } & $-27.173150^{\circ}$ & $-52.437765^{\circ}$ & Dasch 1974 \\
\hline & $-20.079060^{\circ}$ & $-43.505559^{\circ}$ & \\
\hline M. luteocintus Dasch* & $-25.304982^{\circ}$ & $-49.055647^{\circ}$ & Dasch 1974 \\
\hline M. Iuteolus Dasch & $-27.180723^{\circ}$ & $-52.421557^{\circ}$ & Dasch 1974 \\
\hline M. macilentus Dasch* & $-22.464190^{\circ}$ & $-42.993480^{\circ}$ & Dasch 1974 \\
\hline M. magnicrus Dasch* & $-22.942314^{\circ}$ & $-43.465183^{\circ}$ & Dasch 1974 \\
\hline M. medius Dasch & $-27.181784^{\circ}$ & $-52.404584^{\circ}$ & Dasch 1974 \\
\hline M. mulleolus Dasch* & $-27.184364^{\circ}$ & $-52.382179^{\circ}$ & Dasch 1974 \\
\hline M. muscosus Dasch & $-25.436740^{\circ}$ & $-49.219587^{\circ}$ & Kumagai \& Graf 2000 \\
\hline \multirow[t]{2}{*}{ M. nigrifemoratus Dasch* } & $-20.096285^{\circ}$ & $-43.532459^{\circ}$ & Dasch 1974 \\
\hline & $-22.473083^{\circ}$ & $-43.015419^{\circ}$ & \\
\hline M. novateutoniae Dasch* & $-27.202601^{\circ}$ & $-52.377426^{\circ}$ & Dasch 1974 \\
\hline M. paraensis Dasch* & $-1.313651^{\circ}$ & $-49.908955^{\circ}$ & Dasch 1974 \\
\hline \multirow[t]{4}{*}{ M. placitus Dasch } & $-19.924201^{\circ}$ & $-43.934096^{\circ}$ & Dasch 1974 \\
\hline & $-27.203611^{\circ}$ & $-52.401861^{\circ}$ & \\
\hline & $-22.981203^{\circ}$ & $-43.524821^{\circ}$ & \\
\hline & $-22.438879^{\circ}$ & $-43.037920^{\circ}$ & \\
\hline M. planus Dasch* & $-27.199516^{\circ}$ & $-52.339307^{\circ}$ & Dasch 1974 \\
\hline M. praeclarus Dasch & $-27.007423^{\circ}$ & $-52.403445^{\circ}$ & Dasch 1974 \\
\hline M. procerus Dasch & $-27.019865^{\circ}$ & $-52.385024^{\circ}$ & Dasch 1974 \\
\hline M. properatus Dasch & $-25.420287^{\circ}$ & $-49.301463^{\circ}$ & Kumagai \& Graf 2000 \\
\hline M. puteolus Dasch & $-27.030885^{\circ}$ & $-52.402510^{\circ}$ & Dasch 1974 \\
\hline M. repandus Dasch* & $-27.034333^{\circ}$ & $-52.421600^{\circ}$ & Dasch 1974 \\
\hline M. stenotus Dasch* & $-27.045175^{\circ}$ & $-52.425674^{\circ}$ & Dasch 1974 \\
\hline M. taeniatus Dasch* & $-20.133915^{\circ}$ & $-43.500161^{\circ}$ & Dasch 1974 \\
\hline M. verecundus Dasch* & $-25.551058^{\circ}$ & $-49.240400^{\circ}$ & Dasch 1974 \\
\hline M. villosus Dasch & $-27.059294^{\circ}$ & $-52.442001^{\circ}$ & Dasch 1974 \\
\hline
\end{tabular}




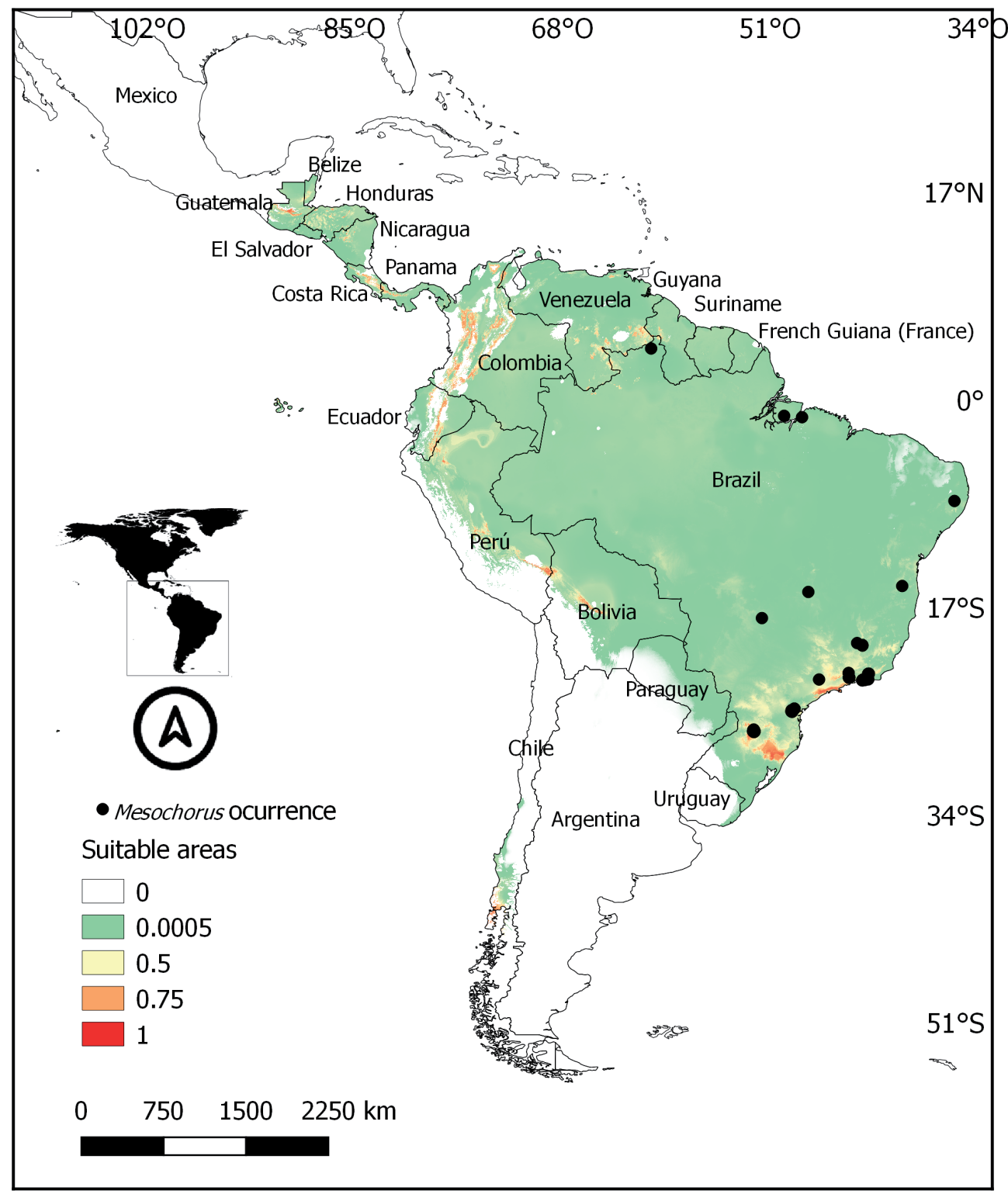

FIGURE 1. Real (black dots) and predicted (colors) geographical distribution of Mesochorus in Brazil based on species distribution modeling by Maxent. / Distribución geográfica real (puntos negros) y predicha (colores) de Mesochorus en Brasil basada en el modelo de distribución de especies por Maxent.

\section{ACKNOWLEDGEMENTS}

We thank the Vicerrectoría de Investigación y Postgrado from the Universidad Católica del Maule for providing the necessary resources for the realization of this project.

\section{REFERENCES}

Anderson, R.P. 2013. A framework for using niche models to estimate impacts of climate change on species distributions. Annals of the New York Academy of
Sciences 1297: 8-28.

Ashfaq, M., Erlandson, M., Braun, L. 2005. Hyperparasitism by Mesochorus spp. (Hymenoptera: Ichneumonidae) in Peristenus sp. (Hymenoptera: Braconidae) and development of PCR primers for hyperparasitoid detection. Biological Control 32: 371-377.

Barve, N., Barve, V., Jiménez-Valverde, A., Lira-Noriega, A., Maher, S.P., Peterson, A.T., Soberón, J., Villalobos, F. 2011. The crucial role of the accessible area in ecological niche modeling and species distribution modeling. Ecological Modelling 222: 1810-1819. 
IBGE. 2004. Brazilians vegetation and biomes maps. Brazilian institute of geography and statistics. URL: http://www. ibge.gov.br. Accessed: January 6, 2018.

Dasch, C.E. 1974. Neotropic Mesochorinae (Hymenoptera: Ichneumonidae). Memoirs of the American Entomological Institute 22: 1-509.

Day, W.H. 2002. Biology, host preferences and abundance of Mesochorus curvulus (Hymenoptera: Ichneumonidae), a hyperparasite of Peristenus spp. (Hymenoptera: Braconidae) parasitizing plant bugs (Miridae: Hemiptera) in alfalfa-grass forage crop. Annals of the Entomological Society of America 95: 218-222.

Elith, J., Phillips, S.J., Hastie, T., Dudík, M., Chee, Y.E., Yates, C.J. 2011. A statistical explanation of MaxEnt for ecologists. Diversity and Distributions 17:43-57.

Fernandes, D.R.R., Santos, B.F., Pádua, D.G., Araujo, R.O. 2018. Ichneumonidae in taxonomic catalog of the Brazilian fauna. PNUD. URL: http://fauna.jbrj.gov.br/fauna/ faunadobrasil/11131. Accessed: June 18, 2018.

Hanson, P.Y., Gauld, I.D. 2006. Hymenoptera de la Región Neotropical. The American Entomological Institute. Vol.77. Gainesville. 994 pp.

Hijmans, R.J., Cameron, S.R., Parra, J.L., Jones, P.G., Jarvis, A. 2005. Very high resolution interpolated climate surfaces for global land areas. International Journal of Climatology 25: 1965-1978.

Kumagai, A.F., Graf, V. 2000. Ichneumonidae (Hymenoptera) from urban and rural areas in Curitiba, Paraná, Brazil. Acta Biológica Paranaense 29: 153-168.

Merow, C., Smith, M.J., Silander Jr, J.A. 2013. A pratical guide to MaxEnt for modeling species' distributions: what it does, and why inputs and settings matter. Ecography 36: 1058-1069.

Morrone, J.J. 2014. Biogeographical regionalisation of the Neotropical Region. Zootaxa 3782: 1-110.

Morrone, J.J. 2015. Biogeographical regionalisation of the Andean region. Zootaxa 3936: 207-236.
Myers, N., Mittermeier, R.A., Mittermeier, da Fonseca, C.G., Kent, J. 2000. Biodiversity hotspots for conservation priorities. Nature 403: 853-858.

Owens, H.L., Campbell, L.P., Dornak, L.L., Saupe, E.E., Barve, N., Soberón, J., Ingenloff, K., Lira-Noriega, A., Hensz, C.M., Myers, C.E., Peterson, A.T. 2013. Constraints on interpretation of ecological niche models by limited environmental ranges on calibration areas. Ecological Modelling 263: 10-18.

Peterson, A.T., Soberón, J., Pearson, R.G., Anderson, R.P., Martínez-Meyer, E., Nakamura, M., Araújo, M.B. 2011. Ecological Niches and Geographic Distribution. Princeton University Press, Princeton, NJ, USA. 328 pp.

Phillips, S.J., Anderson, R.P., Schapire, R.E. 2006. Maximum entropy modeling of species geographic distributions. Ecological Modelling 190: 231-259.

Qiao, H., Soberón, J., Peterson, A.T. 2015. No silver bullets in correlative ecological niche modelling: insights from testing among many potential algorithms for niche estimation. Methods in Ecology and Evolution 6: 11261136.

Say, T. 1835. Descriptions of new North American Hymenoptera, and observations on some already described. Boston Journal of Natural History 1: 210-305.

Tougeron, K., Tena, A. 2018. Hyperparasitoids as new targets in biological control in a global change context. Biological Control. URL: https://www.sciencedirect.com/science/ article/pii/S1049964418301567?dgcid=rss_sd_all. Accessed: July 06, 2018.

Yeargan, K.V., Braman, S.K.1989. Life history of the hyperparasitoid Mesochorus discitergus (Hymenoptera: Ichneumonidae) and tactics used to overcome the defensive behavior of the green cloverworm (Lepidoptera: Noctuidae). Annals of the Entomological Society of America 82: 393-398.

Yu, D.S., van Achterberg, C., Horstmann, K. 2012. World Ichneumonoidea 2011. Ottawa, Taxapad. Database on flash-drive. URL: http://www.taxapad.com. Accessed: January 03, 2018. 